\title{
Eine Hauptstadt auf der Suche nach Stabilität
}

Zehn Bilder vom Wien 1918/1919

Une capitale à la recherche de stabilité. Dix images de Vienne, 1918-1919

A Capital in Search of Stability. Ten Images of Vienna 1918/1918

\section{Alfred Pfoser}

\section{OpenEdition \\ Journals}

Édition électronique

URL : http://journals.openedition.org/austriaca/366

DOI : 10.4000/austriaca.366

ISSN : 2729-0603

\section{Éditeur}

Presses universitaires de Rouen et du Havre

\section{Édition imprimée}

Date de publication : 1 décembre 2018

Pagination : 103-136

ISBN : 979-10-240-1354-1

ISSN : 0396-4590

\section{Référence électronique}

Alfred Pfoser, „Eine Hauptstadt auf der Suche nach Stabilität“, Austriaca [Online], 87 | 2018, Online erschienen am: 01 März 2020, abgerufen am 28 Januar 2021. URL: http://journals.openedition.org/ austriaca/366 ; DOI: https://doi.org/10.4000/austriaca.366 
Alfred Pfoser

Wien

\section{Eine Hauptstadt auf der Suche nach Stabilität Zehn Bilder vom Wien 1918/1919}

Die einst so stolze Metropole des Vielvölkerstaates zählte zu den großen Verlierern des Krieges. ${ }^{1}$ Wien galt nach der Auflösung der Habsburgermonarchie in Europa als ein einzigartiges Modell des urbanen Niedergangs. Die ehemalige Kaiserstadt schien nicht mehr zu dem kleinen, neuen Land zu passen, das von den Siegermächten den alten Namen Österreich aufgezwungen bekam. Wien war eine besiegte Stadt, ohne dass in den Jahren 1914 bis 1918 feindliche Truppen in der Stadt gewesen wären. Die prekäre materielle Versorgungslage und die völlige Abhängigkeit von den Siegermächten wurden als erstrangige Demütigung erlebt. Wie den Untergang in einen Aufbruch, die gescheiterten Ambitionen in gescheitere Absichten verwandeln und den Traum von Größe weiter zu tradieren? Was nun, was tun?

Zehn widersprüchliche Wien-Bilder von den Monaten und Jahren nach der Gründung der Republik. Zehn Ansagen, die in diesem kritischen Moment die Sicht auf die Stadt prägten. Zehn Parolen, die bestimmte Adressaten und bestimmte Absichten hatten, in denen gewisse Gruppen ihre Interessen und Stimmungen ausdrückten. Zehn Erzählungen, die alle mit Nachdruck darauf hinwiesen, dass eine große, alte europäische Hauptstadt nach einer neuen Rolle und vor allem nach Stabilität suchte.

1. Wolfgang Maderthaner, „Von der Zeit um 1860 bis zum Jahr 1945“, in Peter Csendes/Ferdinand Oppl (Hrsg.), Wien. Geschichte einer Stadt. Band 3: Von 1790 bis zur Gegenwart, Wien, Böhlau, 2006, S. 317-360 ; Maureen Healy, Vienna and the Fall of the Habsburg Empire. Total War and Everyday Life in World War I, Cambridge, Cambridge University Press, 2004 ; Alfred Pfoser/Andreas Weigl (Hrsg.), Im Epizentrum des Zusammenbruchs. Wien im Ersten Weltkrieg, Wien, Metroverlag, 2013; Alfred Pfoser/Andreas Weigl, Die erste Stunde Null. Gründungsjahre der österreichischen Republik, Salzburg, Residenz, 2017. 


\section{Die Reichshaupt- und Residenzstadt}

Das Ende des Ersten Weltkriegs hinterließ Wien mit einer gebrochenen politischen Identität. Die Zukunftsperspektiven, nicht zuletzt wegen des Friedensdiktats von Saint-Germain, nahmen sich sehr begrenzt aus. Vorbei die Zeiten, als in der Hofburg und in den Ministerien die Fäden für die Verwaltung eines Riesenreiches gezogen wurden, als Stadtplaner wie Otto Wagner mit Ideen von einer künftigen Vier-Millionen-Stadt spielten, als Wien eine Aura von Glanz, Kompetenz und Innovation verströmte, als Handels-, Finanz-, Wissenschafts- und Kulturzentrum eine privilegierte Stellung im gesamten Habsburgerreich innehatte und eine exorbitante Fülle von Geschäften und ein breiter Dienstleistungssektor die Mittel- und Oberschichten mit Luxus und Behagen versorgte. Die glanzvolle Metropole verlor ihre Bedeutung als Wirtschaftsdrehscheibe und Verwaltungszentrum. Die Grenzen lagen nun in Sichtweite. Aus auch der Traum vom großen Bedeutungsgewinn durch den Krieg, von einer glorreichen Zukunft Wiens, das als internationale Schaltzentrale in einem vom Deutschen Reich dominierten Mittel-, Ost- und Südosteuropa eine Schlüsselrolle einnehmen sollte.

Die neuen Nachbarstaaten, mit denen man früher in einem Reich zusammen gelebt hatte, sperrten in ihrer Entstehungsphase sofort die Grenzen. Die neue Tschechoslowakei drosselte die Kohlenzufuhr, Ungarn die Lebensmittelimporte, Polen lag mit der Tschechoslowakei halb im Krieg und fiel als Lieferant aus, die Konflikte um Kärnten und die Südsteiermark machten Lieferungen aus Jugoslawien zeitweise unmöglich, der Mittelmeerhafen Triest wurde italianisiert. Die alten Warenströme im gemeinsamen Markt der Monarchie, die Wien versorgt und die Wiener Wirtschaft am Laufen gehalten hatten, waren gestört oder gar versiegt. Wien wurde tagtäglich geplagt von Ungewissheit und Unsicherheit, wie auch den täglichen Berichten der Tageszeitungen über die gerade eingetroffenen und aktuell verfügbaren Lebensmittelmengen zu entnehmen war. Fast noch schlimmer als die erschwerte Beschaffung war der Zusammenbruch des Eisenbahnverkehrs, der selbst dann, wenn Verträge abgeschlossen und Kontingente gesichert waren, normale Wirtschaftsbeziehungen paralysierte. ${ }^{2}$

2. Die Zeit, 27.10.1918, S. 9. 
In einer mittel- und längerfristigen Perspektive waren für die Stadt schwere wirtschaftliche Schädigungen zu erwarten. Die Stadt zog in der Monarchie ihren Nutzen daraus, dass der umfangreiche Verwaltungsapparat tausende und abertausende Staatsbeamte ernährte, die Steuern zahlten, die für Beschäftigung in Handel- und Gewerbebetriebe sorgten. In den Jahren 1914 bis 1918 war der Apparat nochmals ausgedehnt worden, schließlich wurden in Wien die Fäden der Kriegsführung und der Kriegswirtschaft gezogen. Mit der Auflösung der Monarchie verlor ein erheblicher Teil der riesigen Beamtenschaft ihre Daseinsberechtigung. Große Staatsbetriebe wie die Staatsbahnen, die Post, die Tabakregie oder die staatliche Lotterie mussten redimensioniert werden. Die Gemeinde Wien verlor damit Millionen Kronen, die bisher als Umlage der Erwerbsteuer an die kommunalen Kassen bezahlt wurden. Für das Budget bedeutete dieser Schwund der Stadt einen schweren Schlag, weil gleichzeitig die Ausgaben für soziale Belange explodierten. ${ }^{3}$

Hinter der Beamtenfrage verbarg sich auch eine nationale Problematik. ${ }^{4}$ Während viele Tschechen, die in untergeordneten Positionen als Portiere, Amtsdiener, Briefträger oder Bahnarbeiter in Wien arbeiteten, entschlossen waren, weiterhin hier in Beschäftigung zu bleiben und ihren Wohnsitz beizubehalten, flüchteten tausende deutschsprachige Beamte, die in Provinzialbehörden und Staatsbetrieben tätig waren, nach Deutsch-Österreich, um sich in ihrer alten Heimat wieder anzusiedeln oder als "deutsche Zuwanderer“ in einem „deutschen Staat" zu leben. Dabei ging es auch darum, wohl erworbene Pensionsrechte geltend zu machen. Jeder Beamte deutscher Nationalität bekam auf Verlangen, ohne Rücksicht auf seinen Wohnsitz und die Art seiner Beschäftigung, die österreichische Staatsbürgerschaft. Auch viele der inaktiv gewordenen, mehrheitlich deutschsprachigen Offiziere der k.u.k. Armee, die bisher ihr Heimatrecht irgendwo im Reich hatten, siedelten sich im neuen Staat an. ${ }^{5}$ Die Übersiedlung dieser Gruppen nach Österreich trug zwar zunächst zur sozialen Beruhigung bei, aber verschob die Problematik auf die Zukunft. Der Kleinstaat konnte auf Dauer den riesigen Beamtenapparat weder beschäftigen noch finanzieren. Die alten k.u.k. Ministerien wirkten zwar als liquidierende Ministerien weiter, aber irgendwann musste die Staatsführung Konse-

3. Die Zeit, 10.11.1918, S. 5.

4. Die Zeit, 30.11.1918, S. 2.

5. Die Zeit, 17.12.1918, S. 4. 
quenzen ziehen und den Beamtenabbau durchsetzen. Nachdem sich die Regierungen jahrelang um das Problem herumdrückten, hatte die Regierung Ignaz Seipels die politische Courage, die Staatsbeamtenfrage anzugehen. Sie nutzte die Völkerbund-Aufsicht bei der Genfer Sanierung, um 100000 Bedienstete aus dem Dienst zu entlassen.

Wien war nicht nur der Sitz der Zentralbehörden, sondern, in Wechselwirkung damit, auch der Knotenpunkt aller wichtigen im Staatsgebiet befindlichen Unternehmen, Banken, Versicherungsgesellschaften und vieler anderer Institutionen. Die neu entstandenen Staaten taten alles, um die herausgehobene Position Wiens auszuhebeln, und zogen alle administrativen Register, um die Zentralstellen der Unternehmen in ihrem eigenen Staat anzusiedeln. Die Nachfolgestaaten wachten eifersüchtig darüber, mittels Nostrifizierungen die alten Bande zu kappen und das „Wiener Finanzkapital" in die Schranken zu weisen, was zu Folge hatte, dass viele Wiener Büros schlossen und Wien tausende qualifizierte Arbeitsstellen verlor. Die Direktionen vieler Gesellschaften und Banken verließen das Land. Mit der Abstempelung der Kronenwährung schufen die Nachbarstaaten Fakten, die alle Hoffnungen auf eine Wiederbelebung des Wirtschaftsraumes (zumindest vorderhand) zerstörten. Die sich ergebenden Grenzkonflikte erzeugten eine Zusatzbelastung.

Noch lange hoffte die Wiener Wirtschaft auf einen Modus Vivendi mit den anderen Nachfolgestaaten, vielleicht auch auf eine Wiederauferstehung der Monarchie in Form eines Staatenbunds. ${ }^{6}$ Denn die Perspektive des Anschlusses an das Deutsche Reich war für Teile der Wiener Wirtschaft kurz- und mittelfristig alles andere als verlockend, war dies doch damit verbunden, der Konkurrenz der leistungsfähigeren deutschen Wirtschaft ausgesetzt zu sein und auf Führungsansprüche zu verzichten. Dankbar nahm sie im Dezember 1918 vage Vorschläge der französischen Regierung auf, einen mitteleuropäischen Wirtschaftsbund zu gründen. Das Projekt des österreichischen Außenministers Otto Bauer, den Anschluss, auch mittels einer Volksabstimmung im Frühjahr 1919, noch rasch vor den Pariser Friedensverhandlungen voranzutreiben, wurde damit auch von österreichischer Seite gestört.

Der gleichzeitig mit der Republikgründung beschlossene Anschluss an das Deutsche Reich stieß in Wien auf ein Geflecht höchst ambiva-

6. Die Zeit, 22.12.1918, S. 1. 
lenter Interessen und Bindungen. Nicht nur die alten politischen, wirtschaftlichen und kulturellen Eliten, auch Teile der Arbeiterschaft hegten große Skepsis, die von alten antipreußischen Komplexen genährt wurde. Schon während des Krieges hatte die „Nibelungentreue“ durch die deutsche Dominanz erheblich gelitten. Die Perspektive, Wien in untergeordneter Funktion, wenn auch mit dem rhetorischen Titelaufputz einer zweiten deutschen Hauptstadt dauerhaft einzurichten, stand quer zu eingeübten Positionen und Traditionen.

\section{Die sterbende Stadt ${ }^{7}$}

Wien galt in den Monaten und Jahren nach dem Ende des Ersten Weltkrieges in der internationalen Welt als Living Museum für urbane Deklassierung. Jakob Reumann, der erste sozialdemokratische Bürgermeister Wiens, fasste die Dramatik der Lage bei seinem Amtsantritt am 22. Mai 1919 in folgende Worte: „Vielleicht keine Stadt der Erde hat infolge des Krieges so viel gelitten wie unser Wien. Nirgends wurde so viel gehungert wie hier, nirgends holt sich die Tuberkulose

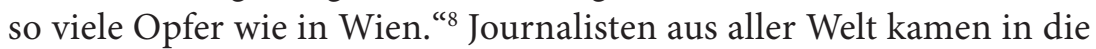
Stadt, um das Elend zu besichtigen und Schilderungen und Hilfsappelle von der "sterbenden Stadt“ zu verbreiten. Mit einer gewissen Verzögerung setzten sich alliierte Militärkommissionen in der Stadt fest, um vor Ort die Lage zu beobachten, mit den führenden Politikern, Unternehmern und anderen führenden Persönlichkeiten des öffentlichen Lebens Kontakt zu halten, ihren Regierungen von den Entwicklungen, Vorfällen und Stimmungen zu berichten und durch Versprechungen und Drohungen unerwünschte politische Optionen zu verhindern. Nicht zuletzt trafen Touristen ein, die die Gelegenheit nutzten, hier mit begehrten Devisen billig leben und einkaufen zu können und von den Einheimischen als rettende Engel wie auch als Aasgeier betrachtet wurden.

7. Vgl. die zeitgenössische Verwendung des Begriffs in Buchtiteln und in den Ausführungen: Victor Gustav Josef Cordon, Die sterbende Stadt: Eine Phantasie, Wien/Leipzig, Harbauer, 1920 ; Rudolf B. Weitzer, Das sterbende Wien, Wien, Waldheimatverlag, 1926 ; Karl Ziak, Wien. Heldenroman einer Stadt, Wien/Leipzig, Fiba-Verlag, 1931.

8. Die Gemeindeverwaltung der Bundeshauptstadt Wien in der Zeit vom 1. Juli 1919 bis 31. Dezember 1922 unter dem Bürgermeister Jakob Reumann, Wien, Wiener Magistrat, 1927, S. 2. 
Das Kriegsgeschehen hatte zwar Wien nicht direkt betroffen, aber gewaltige Zerstörungen anderer Art hinterlassen. Die unmittelbare Nachkriegszeit verbesserte die Situation nicht, sondern verschärfte nochmals die Unbill der Kriegsjahre. Die Erfahrung von Hunger und Kälte, von finsteren Gassen und allgegenwärtiger Kleinkriminalität, die Extremsituationen der alltäglichen Überlebenskämpfe, die demütigenden Erlebnisse des Anstellens und Hamsterns, das Chaos auf den Lebensmittelmärkten mit den sich ständig ändernden Mengen und Bedingungen der Lebensmittelzufuhr, die Drosselung der Kohlenund Gaszufuhr und ihre Folgen für Heizen und Kochen, die Einbußen an Mobilität durch Einstellung der Stadtbahn und Reduktion des Straßenbahnverkehrs, das Gefühl der Isolation wegen des eingeschränkten Bahnpersonenverkehrs, die Erfahrungen von Ablehnung und Ausgrenzung im neuen Staat, die hoffnungslose Überbelegung der Wohnungen und vor allem die große Wirtschaftsrezession, die Wien nach dem Zusammenbruch der Kriegswirtschaft in ein soziales Chaos gestürzt und so viele Beschäftigte, erst recht die Kriegsheimkehrer, in die Arbeitslosigkeit gestoßen hatte, sorgten für Anspannung, Zerrüttung, Depression und Revolutionsstimmung. Wien, einst die märchenhafte Kaiserstadt, bekam - vorerst vergessen von den Alliierten, die ganz auf die deutsche Frage konzentriert waren - international ein neues Label: Wien war der Prototyp einer „sterbenden Stadt“. Das manifeste, viele Jahre verbleibende Symbol für das elende, frierende Wien war der abgeholzte Wienerwald. Tausende schleppten in Rucksäcken, Taschen und Bündeln schlecht brennende Äste und Scheiter nach Hause, um sich ein wenig Wärme zu verschaffen.

Die österreichische Regierung sowie alle Kräfte im Land, die über internationale Netzwerke verfügten (Industrielle, Schriftsteller, Künstler und Intellektuelle), versuchten Alarm zu schlagen, die Welt aufmerksam zu machen über den Ausnahmezustand Wiens. Vor allem empörte man sich in Wien, dass Österreich auch nach dem Krieg mit den Lebensmittelabsperrungen der Entente konfrontiert war und von ihr als Verliererstaat diplomatisch isoliert wurde. Mit den Siegern ins Gespräch zu kommen, Warnungen, Depeschen und Hilferufe abzusetzen und über Kredite und Lieferungen zu verhandeln, war äußerst schwierig. Aber immerhin gelang es, Meinungsmacher nach Wien zu holen und über die Presse die internationale Öffentlichkeit zu informieren.

So begleitete Ende November 1918 Max Winter, der legendäre AZ-Journalist und Wiener Vizebürgermeister der Jahre 1919/20, 
französische, englische, Schweizer und italienische Kolleginnen und Kollegen nach Favoriten, um „dort die Leiden des anderen Wien kennen zu lernen“.9 Sie trafen geschlossene Wärmestuben und erfuhren von überbelegten Notunterkünften, besichtigten leere Magazine, sie besuchten die Märkte in Favoriten, um angesichts der geschlossenen Fleischgeschäfte und spärlichen Gemüsestände festzustellen, dass es nichts gab außer Rüben, Zwiebeln, Knoblauch und gefrorenem Kraut, auch nicht Kartoffeln. Die ausländischen Gäste müssen registrieren, dass "nirgends in der Welt so viel gehungert wird wie in Wien" ${ }^{10}$ Bei einem Fleischhauer auf der Favoritenstraße, der Pferdelungen („Roßbeuschel“) verkaufte, entdeckten die Journalisten Frauen, Kinder und Greise, die in langen Viererreihen angestellt waren. Kinder trugen keine Schuhe, sondern nur Sandalen, hatten die Füße in Fetzen gewickelt. Auch Mütter mit Kleinkindern mussten stundenlang in der Kälte ausharren. Heinrich Leoster, der mit der Journalistengruppe unterwegs war, bilanzierte:

Die ausländischen Journalisten, die zu uns gereist sind, um uns die Knochen am Leib zu zählen, reißen auch wirklich Mund und Augen auf bei dem, was ihnen jetzt in der lustigen Kaiserstadt geboten wird. [...] Durch die schlecht beleuchteten menschenleeren Straßen der 'schönsten Stadt der Welt', in denen die stolzen Prachtbauten hochstaplerisch zu protzen scheinen, führt man unsere Gäste jetzt zu den bleichen, hohläugigen Kinder, vor die Tore der wegen Kohlenund Lebensmittelnot geschlossenen Heilanstalten, in die Kriegsküchen, wo der Mittelstand an den spärlichen Resten des Hungertuches nagt. ${ }^{11}$

Immerhin gab es in Folge der internationalen Berichterstattung Lebensmittellieferungen aus Italien und aus der Schweiz. Wiener Kinder wurden zu Zehntausenden in die Schweiz, nach Italien, nach Holland verschickt. Einzelne amerikanische Hilfsorganisationen (etwa die Quäker) nahmen ihre Arbeit in Wien auf. Erst im März 1919, als auch in Wien eine Räteregierung wie in Budapest und München drohte, nahm die Entente die verheerende Situation in Wien richtig zur Kenntnis, beendete den Lieferboykott und nahm Lebensmittellieferungen auf. Mit Begeisterung wurden Mitte Mai 1919 in der Wiener Bevölkerung die Amerikaner empfangen, die eine umfangreiche Kinderhilfsaktion starteten und über ganz Wien ein Netz von Aus-

9. Max Winter, „Das hungernde Wien“, in Arbeiter-Zeitung, 29.11.1918, S. 6.

10. Ebenda.

11. H. Leoster, „Unsere Kriegsausstellung“, in Die Zeit, 30.11.1918, S. 1. 
speisungsaktionen einrichteten. Bereits im Juli 1919 wurden in den Massenausspeisungen über 100.000 Portionen am Tag ausgegeben. ${ }^{12}$

Der anhaltende Ausnahmezustand zeigte sich unter anderem darin, dass das im Krieg eingeführte, immer mehr ausgeweitete Kartensystem für Güter des täglichen Bedarfs bis 1922 beibehalten werden musste; immerhin war dadurch eine minimale Basisversorgung garantiert. Der Verwaltungsbericht der Stadt Wien hielt retrospektiv fest: „Erst im Laufe des Jahres 1920 erfuhren die Verhältnisse eine derartige Besserung, dass mit dem allmählichen Abbau der öffentlichen Bewirtschaftung begonnen werden konnte ${ }^{\text {“ }}{ }^{13}$

\section{Eine Stadt im Aufruhr}

Man kann die aufrührerische Stimmung in den Monaten und Jahren von 1918 bis 1922 auch in einem größeren zeitlichen Rahmen sehen. Lutz Musner und Wolfgang Maderthaner haben in ihrem Buch Die Anarchie der Vorstadt die anarchischen Vorfälle am 11. September 1911 genauer untersucht. Eine geordnete Demonstration gegen die Teuerung entgleiste an diesem Tag in wilde Destruktivität. Geplünderte Geschäfte, Steinattacken gegen das Rathaus, zertrümmerte Gaslaternen, umgeworfene Straßenbahnwaggons und ein Sturm auf zehn Ottakringer Schulen belegten, welche Wut sich in den Vorstädten angesammelt hatte. Vor allem Jugendliche waren an dem unkontrollierten Treiben beteiligt, Frauen solidarisierten sich mit ihnen. Die Bilanz von zwei Toten und jeder Menge Schaden schockierte die Stadt.

Als sich während des Krieges die Versorgungsprobleme immer mehr zuspitzten und sich in den Nächten hunderttausende Menschen bei Geschäften und Marktständen anstellen mussten, war die Polizei nie fern, um jeder möglichen Revolte zuvorzukommen. Je länger der Krieg dauerte, desto mehr spitzten sich die Zwischenfälle zu, wurden Kleinkriminalität, gezielte Überfälle auf Geschäfte oder Attacken auf voll beladene Gespanne zur Normalität der Stadt im Krieg. Drohend marschierten ganze Fabrikbelegschaften in Richtung Innenstadt und

12. Wiens Kinder und Amerika. Die amerikanische Kinderhilfsaktion 1919, hrsg. vom Deutschösterreichischen Jugendhilfswerk in Wien, Wien, Gerlach \& Wiedling, 1920, S. 146-163.

13. Gemeindeverwaltung vom 1. Juli 1919 bis 31. Dezember, op. cit., S. 523. 
Rathaus, um höhere Brotrationen zu erzwingen. Wieder waren es vor allem Jugendliche, die den Ton der Auseinandersetzungen vorgaben, wiederum wurden sie von Frauen unterstützt. Die tendenziell anarchistische Stimmung beschäftigte jedenfalls intensiv die Polizei. Mit den großen Jännerstreiks 1918 bekam der Protest eine neue Qualität. Es ging zwar in erster Linie um Forderungen wie die Erhöhung der Mehl-, Brot- und Kohlerationen oder die Verbesserung der Arbeitsbedingungen, aber sie waren nun eingebettet in politische Forderungen.

In den Tagen vor und bei der Republikgründung ließen sich wieder, mit fließenden Übergängen, die zwei bekannten Varianten der Masse beobachten. Die ungeordnete Masse mit ihrem destruktiven, anarchistischen Potential, und die geordnete Masse, die sich einem klaren einheitlichen politischen Willen unterordnete. Sozialdemokratische Politikerinnen und Politiker waren ständig damit beschäftigt, die Lage unter Kontrolle zu halten, an die Geduld zu appellieren und die bereits erreichten Erfolge zu preisen. Abgesehen von den schnell scheiternden, sehr begrenzt agierenden kommunistischen „Putschversuchen" am Gründonnerstag und im Juli 1919 blieb Wien von großen Rebellionen, spontanen Revolten und anarchistischen Verwüstungen verschont. Die Arbeiter-Zeitung streute dem Proletariat Ende 1921 retrospektiv Rosen: „Die Wiener Arbeiter haben in den letzten drei Jahren wahrlich schier übermenschliche Einsicht, Besonnenheit, Geduld bewiesen. ${ }^{\text {"14 }}$

Wie gefährlich die Situation war, zeigte sich bereits bei den Demonstrationen vor dem Niederösterreichischen Landhaus am 30. Oktober 1918, als es nach Auflösung der Kundgebung zu wüsten Ausschreitungen im Kaiviertel kam. Demonstranten zerschlugen Fensterscheiben von mehreren Caféhäusern, drangen in die Lokale ein und zerstörten das Interieur. Offizierskader der alten Armee boten der Regierung ihre Hilfe an, aber die staatlichen Autoritäten waren machtlos. In der Innenstadt, vor allem vor dem Kriegsministerium und der Rossauer Kaserne, kam es zu erregten Szenen, als Demonstranten - wieder waren es auffallend viele Jugendliche - Soldaten und Offiziere zwangen, ihre Rang- und Ehrenzeichen von den Kappen zu entfernen. Wer sich wehrte, wurde von der Menge attackiert. Ein General, der mit seinem Säbel drohte, musste fliehen. Tausende zogen ohne sichtliche

14. Arbeiter-Zeitung, 2.12.1921, S. 1. 
Ordnung mit roten Fahnen vor das Parlament und skandierten fortwährend: „Hoch die Republik!“ und „Nieder mit der Regierung “. ${ }^{15}$

Nach diesen Ereignissen gab es nur mehr eine Option: die Ausrufung der Republik. Wer sie durchsetzte, war allerdings völlig offen. Die unkontrollierte Masse auf der Straße unter Anführung einzelner Agitatoren oder die 1911 gewählten Parlamentarier der Deutsch-Österreichischen Nationalversammlung. Der Tag der Republikgründung, der 12. November, wurde zu einer der größten Demonstrationen in der Geschichte Österreichs, freilich auch zu einer Blamage, weil die Rote Garde die durchchoreographierte Veranstaltung störte, eine Massenpanik ausbrach und zwei Tote und viele Verletzte zurückließ.

Das aufrührerische Wien stand unter starker internationaler Beobachtung, immerhin bestand im Frühjahr 1919 die Möglichkeit, dass sich eine geographisch zusammenhängende Kette von Räterepubliken von Budapest bis München bildete und der vorhandene revolutionäre Furor auch in Wien zündete. Die österreichische Regierung versuchte mit einer Reformpolitik die revolutionäre Versuchung abzuwehren. In aller Schnelle wurde ein Arbeitslosengesetz erlassen, um die 100000 Betroffenen in Wien ruhigzustellen. Das Kriegsinvalidengesetz hegte die Erregung unter den versehrten Heimkehrern ein. Auch konnte die Regierung mit der umfangreichen Sozialgesetzgebung Versprechen für die „soziale Demokratie“ der Zukunft vorweisen. Das Zusammenspiel von Regierung, Volkswehr und Polizei ließ die beiden kommunistischen Putschversuche scheitern. Auch nach dem Zusammenbruch der Räterepubliken in München und in Budapest war die revolutionäre Entschlossenheit keineswegs endgültig gestoppt und das anarchistische Potenzial noch lange nicht beseitigt, wie auch später der Brand des Justizpalastes am 15. Juli 1927 zeigen sollte.

Wie sehr die Situation in den Jahren der Republikgründung angespannt war und jederzeit entgleisen konnte, zeigten die Krawalle des 1. Dezember 1921, die die Innenstadt verwüsteten. ${ }^{16}$ Es begann mit Arbeitsniederlegungen in Floridsdorfer Fabriken. Die Streikenden machten sich auf den Weg in die Innenstadt, um gegen Hyperinflation, Wucher, Spekulationsgewinne und Lebensmittelmangel zu demonstrieren. Auf den mitge-

15. Die Zeit, 31.10.1918, S. 3f.

16. Marie-Noëlle Yazdanpanah, „Randale im Bristol. Das Grandhotel als Bühne der Auflehnung“, in Zeitgeschichte, 44. Jahrgang, Juli/August 2017, S. 231-244. 
brachten Transparenten dominierte die Botschaft: „Nieder mit den Schiebern!" Bereits auf dem Weg in die Innenstadt gab es Ausschreitungen. Im Zentrum versuchten kleinere Gruppen das Parlament zu stürmen, was aber verhindert wurde. Eine schnell zusammengestellte Delegation mit Otto Bauer und Friedrich Adler versuchte Bundeskanzler Johannes Schober zu Zugeständnissen zu bewegen. Aber der Aufstand hatte längst anarchische Formen angenommen, geriet völlig außer Kontrolle. Die große Wut tobte sich an Banken, Feinkostläden, dem Schwarzenbergkasino oder den Ringstraßen-Hotels aus. Hotelgäste wurden beraubt, Passanten geplündert, Autofahrer angegriffen. Mehr als 170 Betriebe und Geschäfte waren von diesen Plünderungen betroffen, 330 Personen wurden wegen Hausfriedensbruch, Sachbeschädigung oder Diebstahl festgenommen. Wien stand unter Schock. Der „Mob“"17, so die Diktion der bürgerlichen Presse, hatte zugeschlagen.

\section{Der Wasserkopf}

In der Vorkriegszeit sah nicht nur die deutschsprachige Bevölkerung im habsburgischen Wien den geistigen, politischen und wirtschaftlichen Mittelpunkt des Reiches, der der Stadt immer neue Zuwanderer zutrieb. Wien war der gute Markt, wo es ein zahlungskräftiges Publikum gab, Wien war der Konsumort von zwei Millionen Menschen, von dem viele Produzenten im gesamten Habsburgerreich gut leben konnten. 1918 verkehrte sich die Rolle ins Gegenteil. Wien mutierte zum Moloch, der den anderen Nachfolgestaaten des aufgelösten Reiches im Wege stand, der den Bundesländern des neuen Deutschösterreich die Lebensmittel, die ja nirgendwo im Überfluss vorhanden waren, wegnehmen wollte, der die Bauern daran hinderte, zum besten Schwarzmarktpreis zu verkaufen. Es erschien als „die gehasste Stadt“. ${ }^{18}$

Tschechische Politiker kommentierten den Niedergang der Metropole voller Häme: Edvard Beneš, der tschechische Außenminister, hielt in einem Interview eine Halbierung der Wiener Bevölkerung im

17. Friedrich Austerlitz, „Der Mob“, in Friedrich Austerlitz, Austerlitz spricht, Ausgewählte Aufsätze und Reden, hrsg. von Julius Braunthal, Wien, Verlag der Wiener Volksbuchhandlung, 1931, S. $325 f$.

18. Friedrich Austerlitz, „Los von Wien!“, in Der Kampf. Sozialdemokratische Monatsschrift, 7. Juni 1919, Nr. 10, S. 346. 
nächsten Jahrzehnt für gut möglich; Jan Koloušek, Professor des Prager Polytechnikums, empfahl den Wienern in einem Interview mit einem Londoner Wochenmagazin die Auswanderung, weil es ohne Perspektive sei, in einer parasitären Stadt zu leben. Die Bundesländer des neuen Staates empfanden es als Last, die Stadt zu versorgen und zu ernähren. ${ }^{19}$

In den Jahren 1918 bis 1920 war es denkbar schwierig, alte Verbindungen aufrecht zu erhalten. Die Grenzübertritte in die neuen Nachbarstaaten gestalteten sich als Hindernislauf; der unregelmäßige Zugverkehr und das Pass- und Visawesen errichteten hohe Hürden. Die Wiener Sommergäste, die im Juli und August Geld aufs Land brachten, wurden nun in den Bundesländern als „lästige Mitesser" erachtet, als „Leute, die den Einheimischen sozusagen den Bissen vom Munde wegnehmen, die man also nicht mehr einladet, vielmehr sich mit allen Mitteln vom Leibe zu halten sucht. ${ }^{\prime 20}$ Die Situation wurde noch verworrener, als sich teilweise sozialdemokratische Arbeiter- und Soldatenräte in Feldkirch, Triest, aber auch in Mödling und Liesing gegen den Abtransport von Vieh nach Wien wehrten, weil auch die Bevölkerung in den Klein- und mittleren Städten in ihren Bundesländern an Hunger litt. ${ }^{21}$

Die Metropole Wien, einst eine Schöpfung des Imperiums, war nun sein Überbleibsel. Nie hätte, so hörte man nun allseits, ein Staat von sechs Millionen Einwohnern eine Hauptstadt von zwei Millionen hervorbringen können. Um seinen Abscheu vor dieser Last kundzutun, wurde Wien das Etikett „Wasserkopf“ umgebunden. Die sogenannte Provinz erwies sich als außerordentlich findig, sich in administrativen Absperrmaßnahmen, in politischen Sezessionsbestrebungen von ihrer verarmten Bundeshauptstadt abzusetzen. Wenn die Länder im Juni 1919 den Ruf „Los von Wien“ erschallen lassen, dann, so Friedrich Austerlitz, der Chefredakteur der Arbeiter-Zeitung, sollten sie nicht vergessen, dass das Problem, das Deutschösterreich derzeit mit Wien habe, nur ein temporäres sei. Wien werde innerhalb eines agrarischen Österreich wieder zur Stadt werden, die produziert, die Güter hervorbringt, die Steuern zahlt, die keinem zur Last fällt.

Die Abneigung der Länder gegen eine leidende, sich quälende Großstadt wurde zur Mobilisierung genutzt. Die sich föderalistisch ausgebende

19. Alfred Pfoser/Andreas Weigl, Die erste Stunde Null, op. cit., S. 73.

20. Friedrich Austerlitz, „Los von Wien“, op. cit., S. 346.

21. Wiener Stimmen, 12.6.1919. 
Propaganda gegen den „Wiener Sozialistenzentralismus ${ }^{{ }^{222} 2}$ pochte bei den ersten Wahlen 1919 auf das „Selbstbestimmungsrecht" der Länder und argumentierte damit, dass die Länder früher dagewesen wären als der Staat. Österreich sei nur als ein freiwilliger Zusammenschluss denkbar, was hieß, dass der Beitritt auch wieder gekündigt werden könne. ${ }^{23}$ Die Debatte um den Föderalismus, die vorerst wenig Konfliktstoff versprach, weil sich alle Parteien weitgehend einig waren, dass Österreich als föderaler Bundesstaat (allerdings nicht nach Vorbild der Schweizer Kantonalverfassung) konstruiert werden sollte, wurde von den Christlichsozialen vom Frühjahr 1919 bis zum Beschluss der neuen Verfassung am 1. Oktober 1920 zum vorherrschenden Thema der österreichischen Politik hochgefahren, um die politische Dominanz der Sozialdemokraten (Sozialgesetzgebung, Sozialisierung, Habsburgergesetze, Heeresverfassung) zu stören. Dazu dienten etwa die diversen Pläne, mittels eines Bundesrates die Macht des Nationalrates einzuschränken. So wurde etwa ventiliert, dass ungeachtet der Bevölkerungszahl im Bundesrat alle Länder in ihm die gleiche Gewichtung besitzen sollten.

In aller Heftigkeit prallten die wirtschaftlichen Interessen von Ländern und Wien, zwischen den Agrargebieten und den Städten, beim Schleichhandel aufeinander. „Wucher" wurde zum großen Politikum. Die Sozialdemokraten wollten mit Maßnahmen gegen den Lebensmittelschmuggel auftreten, weil der staatliche Ankauf zu den amtlich festgesetzten niedrigeren Preisen nur beschränkt funktionierte. Die Sozialdemokraten versuchten den Schwarzmarkt, auf dem die Bauern viel Geld verdienen und Lieferanten es zu einem einträglichen Beruf bringen konnten, mit administrativen Maßnahmen zu unterbinden. Fast täglich wurde in den Zeitungen über Razzien in Wien berichtet, bei denen Güter aller Art beschlagnahmt wurden. Die Volkswehr und die Arbeiter- und Soldatenräte unterstützten in den Ländern die Behörden bei der Requirierung, was Widerstand bei den Bauern auslöste. Der sogenannte „Rucksackverkehr“, den die Arbeiter- und Soldatenräte in den Bahnhöfen mit Durchsuchungen verhindern wollten, wurde von den Christlichsozialen als Möglichkeit des kleinen Mannes verteidigt, „ein paar Kilogramm Kartoffel, Gemüse oder ein Liter Milch"24 nach Wien zu bringen. Wien könne, so ihre Argumentation, von der regulierten Lebensmittelzuteilung nicht leben. Die Reichen werden überdies

22. Reichspost, 22.11.1918.

23. z. B. Wiener Stimmen, 3.4.1919.

24. Reichspost, 24.7.1919. 
vom ,jüdischen Schleichhandel“ bedient. Die Reichspost kommentierte: „Die Leidtragenden der geplanten Verfügung sind die ärmere Klasse und der Mittelstand, Hunderttausende, die Verwandte und Freunde auf dem Lande haben und von diesen bisher unterstützt wurden. ${ }^{25}$

Auch Hotels und Restaurants, die sich bisher am Schwarzmarkt eingedeckt hatten, stellten sich gegen die Einschränkung des „Rucksackverkehrs“. Gastwirte und Kaffeesieder, auch Gemeinschaftsküchen, protestierten heftig. ${ }^{26}$ Sie verwiesen darauf, dass in Wien bereits 1400 Gasthäuser in Folge der Lebensmittelnot geschlossen wären, dass tausende Kellner ihren Job verloren hätten. ${ }^{27}$ Beschlagnahmungen durch Arbeiter- und Soldatenräte würden das Überleben der verbliebenen Gastronomie verunmöglichen. In den Kampf um die politische Hegemonie spielte auch der Streit um die Besteuerung, insbesondere die sogenannte Vermögensabgabe, hinein. Das sozialdemokratische Anliegen einer Vermögensabgabe wurde zur Bedrohung bäuerlichen Eigentums umgemünzt. In der politischen Debatte verfingen alle sozialdemokratischen Verteidigungslinien nicht mehr, weil die Großstadt auf dem Land als ein leicht instrumentalisierbares Feindbild eingesetzt werden konnte.

\section{Die soziale Stadt als wissenschaftliches Projekt}

Schon während des Krieges begannen die diversen Denkschmieden in Wien für die Zeit danach zu arbeiten. Eine aufklärerische Gegenbewegung begann inner- und außerhalb der Sozialdemokratischen Partei. ${ }^{28}$ Die zweite Säule der Wiener Moderne, die die Wissenschaft in enger politischer und sozialer Verflechtung mit der Gesellschaft sah, begann Ideen und Pläne für die Zukunft zu entwickeln. Der Blick auf die verelendete Stadt war die Geburtsstunde vieler medizinischer, psychologischer, soziologischer und politikwissenschaftlicher Neuansätze. Viele, oft jüdische Exponenten dieser zweiten österreichischen Moderne dockten, in festerer oder lockerer, nicht immer friktionsfreier Form, an die austromarxistische Reformbewegung in Wien an.

\footnotetext{
25. Ebenda.

26. Neue Freie Presse, 30.7.1919.

27. Die Zeit, 17.2.1919, S. 3.

28. Ernst Glaser, Im Umfeld des Austromarxismus. Ein Beitrag zur Geistesgeschichte des österreichischen Sozialismus, Wien, Europaverlag, 1981.
} 
Das sichtbare, tagtäglich erlebte Elend, vor allem die prekäre Lage der Kinder wurden zum Anstoß für viele praktische Initiativen, aber auch für die theoretische Beschäftigung mit Ernährung und Erziehung in einer Mangelökonomie. Wissenschaft, Sozialreform und neue Lebensgestaltung schienen in der spätaufklärerischen Wiener Moderne eine Einheit einzugehen. Nicht zuletzt trieb das antisemitische Klima an den österreichischen Universitäten die jüdische Intelligenzija in eine Nähe zur Sozialdemokratie. Ein starkes politisches Dokument dieser losen Symbiose war die „Kundgebung des geistigen Wien“ in der Arbeiter-Zeitung aus dem Wahlkampf des Jahres 1927, in der etwa Sigmund Freud, Arthur Schnitzler oder Karl Bühler - abseits jedes politischen Dogmas - ihre Sympathie für die Aufbauarbeit des Neuen Wien kundtaten. ${ }^{29}$

Eine Schlüsselfigur dieser nicht-marxistischen Sozialreform war der zu diesem Zeitpunkt hochbetagte Josef Popper-Lynkeus (1838-1921), dessen Idee von der "allgemeinen Nährpflicht" des Staates (statt der „allgemeinen Wehrpflicht") in den bürgerlich-aufklärerischen, pazifistischen Diskursen weite Verbreitung und Popularität fand. ${ }^{30}$ Popper-Lynkeus hielt wenig von der marxistischen Geschichtsauffassung, glaubte nicht an die besondere Mission des Proletariats, strebte keine Vollsozialisierung an, sperrte sich dagegen, den Kampf gegen Hunger, Not und Angst mit dem unüberschaubaren Großunternehmen einer gesamtgesellschaftlichen Umgestaltung zu verknüpfen. Popper-Lynkeus war mit Skepsis erfüllt gegen den Parteienstaat, gegen die großen theoretischen Gewissheiten, die utopischen Großkonstruktionen und „wissenschaftlichen" Großsysteme, die alle Unzukömmlichkeiten der menschlichen Gesellschaft zu lösen versprachen. Die Sozialreform münzte den sarkastischen Vorwurf Ludwig Börnes auf die Sozialisten aller Länder und Richtungen um: „Wenn der Deutsche einen Fleck aus seinem Kleide ausputzen will, so studiere er vorher Chemie. “"31 Die Sozialreform orientierte sich ganz an praktischer Sozialtechnik, erblickte in der im Weltkrieg erprobten Organisation von Planwirtschaft und Rationierung ein Modell für staatliche Eingriffe zum Wohl des Einzelnen.

29. Alfred Pfoser, Literatur und Austromarxismus, Wien, Löcker, 1980, S. 179-183.

30. Ingrid Belke, Die sozialreformerischen Ideen von Josef Popper-Lynkeus (1838-1921) im Zusammenhang mit allgemeinen Reformbestrebungen des Wiener Bürgertums um die Jahrhundertwende, Tübingen, J. C. B. Mohr, 1978.

31. Josef Popper-Lynkeus, Eine Auseinandersetzung mit dem Sozialismus und den Sozialisten, Wien, Verlag Verein „Allgemeine Nährpflicht“, 1920, S. 4. 
Popper-Lynkeus hatte auf alle materiellen Probleme der Nachkriegszeit eine in seinen Augen denkbar einfache Antwort, nämlich die Güter des zum Leben Notwendigen vom Überflüssigen zu trennen und die Sicherung der Lebenshaltung vom Staat als Grundaufgabe zu fordern. Im Programm der „allgemeinen Nährpflicht“ werde einerseits mittels einer Zwangswirtschaft eine Art Grundsicherung („Kost und Quartier") garantiert, gleichzeitig aber wollte sie die freie, kapitalistische Privatwirtschaft nicht antasten. Statt einer mehrjährigen „Wehrpflicht“ sollte es einen mehrjährigen Sozialdienst geben, der die "Nährpflicht“ absicherte.

Als praktisches Beispiel für die enge Zusammenarbeit zwischen Wissenschaft und Politik sei das parteipolitisch ungebundene Wirken des Mediziners Clemens Pirquet ${ }^{32}$ hervorgehoben, der aus einer patrizisch-jüdischen Familie stammte und wegen seiner Forschungen im Bereich der Immunologie (Impfungen, Allergien) und der Kinderheilkunde eine große internationale Karriere durchlief. So wurde er 1908 an die Johns-Hopkins-Universität in Baltimore engagiert. Von 1911 bis an sein Lebensende 1929 war er Vorstand der Wiener Universitätsklinik für Kinderheilkunde. 1928 wurde er in den Zeitungen als unabhängiger Kandidat für die Wahl des Bundespräsidenten gehandelt.

Schon während der Jahre 1914-1918 beschäftigte sich Pirquet mit der schwierigen Ernährungssituation bei Kindern und Jugendlichen, mit Unterernährung, Mangelkrankheiten, Untergewicht und vermindertem Wachstum und setzte sich mit den Möglichkeiten und Notwendigkeiten der Nahrungsauswahl und Nahrungszufuhr auseinander. In Kriegsspitälern und der Wiener Universitätsklinik entwickelte er erfolgreich ein ausgefeiltes System der Essenszusammensetzung, das beim Start der Amerikanischen Kinderhilfsaktion Massenanwendung erhielt. Pirquet wurde zum wissenschaftlichen Leiter der Amerikanischen Kinderhilfsaktion bestellt, die in Wien für die verschiedenen Altersgruppen und unterschiedlichen Bedürfnisse täglich 100000 Portionen ausgab und dabei eng mit der Stadtverwaltung zusammenarbeitete. Die ernährungswissenschaftliche Zusammenstellung der Mahlzeiten geschah nach seiner Expertise, die auch darauf achtete, dass alle Faktoren beim Gesundungsprozess berücksichtigt wurden. Pirquet hatte schon vorher

32. Gabriele Dorffner/Gerald Weippl, Clemens Freiherr von Pirquet. Ein begnadeter Arzt und genialer Geist, Strasshof, Vier-Viertel-Verlag, 2004. 
auf die besondere Wirkung der Ferienaufenthalte und Sommeraktionen bei der Prävention der Tuberkulose aufmerksam gemacht und an der organisatorischen Umsetzung mitgearbeitet.

Bei der Nahrungswahl kam es nach Pirquet nicht so sehr auf die Menge als auf den Gehalt und die verschiedenen Kalorienwerte an, um optimale Ergebnisse zu zeitigen. Je nach Körpergröße und Sitzhöhe (und nicht nach dem Gewicht) wurden die benötigten Mengen an Eiweiß, Fett oder Zucker ausgerechnet. Pirquets System, im Austausch mit der internationalen ernährungswissenschaftlichen Community entwickelt, reagierte auf den Fettmangel und wies nach, dass dieser in begrenztem $\mathrm{Maß}$ auch durch hochwertige Kohlenhydrate ersetzt werden konnte. Bei Eiweiß war diese Möglichkeit nicht gegeben.

Pirquet entwickelte Handbücher, die seine Theorie ausführlich darlegten; er verfasste massentauglich verfasste Broschüren, mit denen mittels Tabellen die optimale Nahrungsmenge und Nahrungszusammensetzung ausgerechnet werden konnte. Auch Hausfrauen sollten in diesem allseitig auf Rationalität und Rationalisierung abgestellten System Informationen einholen können, wie sie beim Einkauf auf das Verhältnis von Nährwert und Preis achten und berücksichtigen konnten, dass ein Kilogramm Gurke nur den Nährwert von $200 \mathrm{ml}$ Milch hatte. ${ }^{33}$

\section{Die Kulturmetropole}

Der Kulturbetrieb ${ }^{34}$ führte immer ein Eigenleben und schien auch nach der Republikgründung oft losgelöst von der Zeit. Theater spielten die bekannten Stücke der Welt- und Unterhaltungsliteratur, die Oper führte den Repertoirebetrieb weiter, die Konzerthäuser waren voll. Die Kultureinrichtungen brauchten sich um Nachfrage nicht zu sorgen, sondern plagten sich mit Fragen der Stromversorgung und des Kohlenmangels ab. Immer wieder mussten sie gesperrt werden. In den Monaten nach der Republikgründung war der Staat in der Kulturpolitik hauptsächlich damit beschäftigt, ob und wie die Theater, die Oper, die Konzerthäuser und die Museen unter den allgemeinen desolaten Bedingungen wirtschaftlich weitergeführt werden konnten, ob und wie

33. Wiens Kinder und Amerika. Die amerikanische Kinderhilfsaktion 1919, op. cit., S. 120-146.

34. Gertrud Pott, Verkannte Größe. Eine Kulturgeschichte der Ersten Republik 1918 - 1938, Wien, Kremayr \& Scheriau, 1990. 
die Hoftheater und Hofmuseen in Staatstheater und Staatsmuseen verwandelt und als solche finanziert würden. Desgleichen hatten die privaten Theater enorme Probleme, ihre lange funktionierenden Geschäftsmodelle nach der Auflösung der Monarchie beizubehalten. ${ }^{35}$

Die wohl größte Aufregung verursachte im Februar 1919 die italienische Militärkommission, die vierundsechzig Bilder, die in den Jahren 1816 und 1838 von Venetien ins Wiener Hofmuseum und in die Gemäldegalerie der Akademie der bildenden Künste gebracht wurden, nach Italien zurückholen wollte. Eine ähnliche Aktion erfolgte in der Österreichischen Nationalbibliothek, wo die italienische Militärkommission die Auslieferung alter Handschriften aus dem 15. und 16. Jahrhundert zurückforderte. ${ }^{36}$ Der Protest gegen diese Annexion war weitgehend erfolgreich, der Status der Wiener Museen wurde bei den Friedensverhandlungen in Saint-Germain gegen alle Begehrlichkeiten der Nachbarstaaten weitgehend erfolgreich verteidigt. Eine heftige Diskussion löste der Plan aus, Gobelins aus den staatlichen Museen zu verkaufen und damit Lebensmittellieferungen zu finanzieren. ${ }^{37}$

Weniger der Spielplan als die in Zeitungen oft thematisierte materielle Not der Kulturarbeiter erinnerte die Öffentlichkeit daran, in welch einer Umbruchszeit die Theater arbeiteten. Aufbruch und Untergang, Elend und Not in den Jahren des Zusammen- und Umbruchs schienen bei oberflächlicher Betrachtung keinerlei Auswirkungen auf die Produktion zu haben. Die Theater ließen angesichts der Unzahl der Uraufführungen Kritiker und Publikum nicht zu Atem kommen. Viele Schauspieler sicherten sich das Überleben durch Mehrfachbeschäftigung und Engagements im hektisch produzierenden Film- und Kabarettbetrieb. Der schnelle Verfall des Geldes setzte den ganzen kulturellen Betrieb in Atemlosigkeit und Spannung, wie Stefan Zweig in seiner Autobiographie in farbigen Schilderungen festhielt. ${ }^{38}$

Noch ein anderes Thema aus der Theaterwelt beschäftigte intensiv die damalige Öffentlichkeit. In fast allen Zeitungen, egal welcher politi-

35. Julia Danielczyk/Birgit Peter, „Zufluchtsort Theater. Theaterstadt Wien 1918 bis 1920“, in Helmut Konrad/Wolfgang Maderthaner (Hrsg.), Das Werden der Ersten Republik. ... der Rest ist Österreich, Band II, Wien, Gerold, 2008, S. 197-216.

36. Die Zeit, 12.2.1919, S. 1, 12.3.1919, S. 3 ; Hans Tietze, Die Entführung von Wiener Kunstwerken nach Italien, Wien, Schroll, 1919.

37. Siehe etwa Karl Kraus, „Brot und Lüge“, in Die Fackel, Mitte November, 1919, S. 16.

38. Stefan Zweig, Die Welt von gestern. Erinnerungen eines Europäers, Frankfurt/Main, Fischer Taschenbuch Verlag, 1974, S. 216. 
schen Ausrichtung, war die Polemik gegen das neue Theaterpublikum ein Gemeinplatz. Die Klage über das teilweise Ausbleiben der traditionellen Theatergeher und über exorbitante Eintrittspreise vermengte sich mit der Abscheu über ein neues Publikum, das sich im Theater nicht zu benehmen wusste, sich aufdringlich kleidete, alle üblichen Regeln des Anstands ignorierte, seinen Reichtum protzig zur Schau stellte und keinen Sachverstand besaß. In den rechtsradikalen Untergangsszenarien wurde diese Umschichtung mit einem aggressiven Antisemitismus und einem ausgeprägten Hass vermischt; das partielle Fernbleiben des Adels und des Bildungsbürgertums wurde als republikanische Degenerierung diagnostiziert.

Es gehört zu den merkwürdigen Phänomenen der Umbruchszeit, dass Wien trotz der schlimmen Versorgungskrise an der Zuschreibung, eine der ganz großen Kulturmetropolen in der Welt zu sein, mit großer Kraftanstrengung festhielt. Die ehemalige Reichshaupt- und Residenzstadt war mit aller Emphase fest entschlossen, weiterhin zu zeigen, dass es in der internationalen Welt weiterhin als Stadt der Künste, der Musik, der Theater, der kulturellen Begegnung, als Stadt der großen Geister und des guten Geschmacks zu gelten habe. Diese Tradition schaffte Selbstbewusstsein und Zukunftsgewissheit, befeuerte den Glauben, den traurigen Nachkriegsalltag bald überwinden zu können. Natürlich spielte bei dieser angestammten Rolle auch die Ausrichtung auf den Fremdenverkehr mit.

Die Opernhäuser, Theater, Konzertsäle und Museen, die im Boom der Reichshaupt- und Residenzstadt gegründet wurden, bildeten den steinernen Beweis für die besondere Rolle des Wiener Kulturlebens. Eine Diskussion, ob denn der in der k. k. Zeit entstandene Kulturbetrieb redimensioniert werden sollte, fand (mit wenigen Gegenreden) nicht statt. Adolf Vetter, der führende Theatermanager der Republik, setzte klar auf die Fortführung der Hoftheater als Staatstheater, beschäftigte sich zwar zwecks Auslastung des Ensembles mit der Ausweitung des Spielbetriebs (Akademietheater, Schönbrunner Schloßtheater, Redoutensäle), sinnierte über die Zusammenlegung von Staatsoper, Theater an der Wien und Volksoper nach oder plante die Gründung einer eigenen Filmgesellschaft, um aus dem Film-Boom vermehrt Einnahmen zu lukrieren. Die politischen Eliten waren sich darin einig, dass alles nur Erdenkliche getan werden müsse, um die notwendigen Mittel bereitzustellen und den Kulturbetrieb des neuen Staates im alten Umgang weiterzuführen. 
Es war von großer symbolischer Bedeutung, dass Wien in der zugespitzten Kohlen- und Energiekrise des Dezember 1918 zwar die Schulen sperrte und die privaten Haushalte in der Kohlen-, Gas- und Stromzufuhr stark beschränkte, aber viele Initiativen ergriff, um die Theater und die Opernhäuser nach Möglichkeit offen zu halten. Es gab auch viele Schließtage (im Oktober etwa 11 Tage wegen der Grippeepidemie, im Dezember 25 Tage wegen Kohlenmangels), aber eine längere, totale Sperre wurde verhindert. Natürlich ging es da auch darum, den riesigen Kulturbetrieb in Gang zu halten, den Schauspielern und Sängern Beschäftigung zu geben und sie vor dem Hunger zu bewahren, aber darüber hinaus hatte die (zumindest zum Teil) abgesagte Drosselung des Theaterbetriebs auch hohen Symbolgehalt. Sie sollte eine starke Manifestation sein, dass trotz der erzwungenen Beschränkung der Industrieproduktion oder des Straßenbahnverkehrs Theater und Kinos und das in ihnen stattfindende Gemeinschaftserlebnis den Lebenswillen dieser Stadt unter Beweis stellen sollten. ${ }^{39}$

Gleichzeitig mit ihrer Umwandlung in Staatsbetriebe wurde an den ehemaligen Hofbühnen, zum Teil noch in der Generalintendanz von Leopold von Andrian (bis 24. November 1918) vorbereitet, ein künstlerischer Aufbruch signalisiert. Zeitgleich mit der Konstituierung einer deutschösterreichischen Regierung wurde im Oktober 1918 ein Wechsel in der Führung der Hofoper und des Hoftheaters angekündigt. Während in Wien auf der großen politischen Bühne das Drama von der Auflösung des Habsburgerreiches gespielt wurde, endete in der Hofoper die Amtszeit von Hans Gregor, der seit 1911 das Haus routiniert und durchaus erfolgreich geleitet hatte. Das neue Direktorengespann Franz Schalk und Richard Strauss sollte der Wiener Oper im internationalen Musikbetrieb wieder Glanz und Geist einhauchen und die große Tradition des Hauses wieder beleben. ${ }^{40}$

Auch beim Burgtheater ${ }^{41}$ blieb die Repräsentationsfunktion unangetastet, sie führte aber schnell zu Konflikten. Der Anspruch der eigenen künstlerischen Exzellenz kollidierte mit der internationalen Ausstrahlung Max Reinhardts, der mit seinen Berliner Aufführungen und seiner Direktion am Deutschen Theater der Theaterstadt Wien längst Ruf und

39. Die Zeit, 14.12.1918, S. $3 \mathrm{f}$

40. Paul Stefan, Die Wiener Oper, Wien, Wila Wiener Literarische Anstalt, 1922, S. 86-95 ; Marcel Prawy, Die Wiener Oper. Geschichte und Geschichten, Wien, Molden, 1969, S. 190-220.

41. Rudolph Lothar, Das Wiener Burgtheater. Ein Wahrzeichen österreichischer Kunst und Kultur, Wien, Augartenverlag, 1934, S. 406-451. 
Rang genommen hatte. Die Beteiligung an der Gründung der Salzburger Festspiele (Planungen bereits 1917, erste Aufführungen August 1920) galt als Reinhardts erster Schritt der Rückkehr nach Österreich. Schon seit 1917 gab es Bestrebungen, ihn für das Burgtheater zu gewinnen und wieder nach Wien, in seine Heimatstadt, zurückzubringen. Nach dem Krieg wurden die Gespräche intensiviert, im Januar 1921 gab es erste vertragliche Vereinbarungen, aber ein von Direktor Albert Heine angestrebtes Engagement scheiterte daran, dass sich das angestammte Ensemble gegen eine Übernahme wehrte. Reinhardt wollte Teile seines Ensembles mitbringen. Seine Vorstellungen konnte er, nach ersten Pilotprojekten in den Redoutensälen (1922), erst mit der Übernahme des Theaters in der Josefstadt (1924) realisieren. ${ }^{42}$

\section{Das schwarze Wien ${ }^{43}$}

Noch in den 1920er Jahren hielt der Lueger-Kult an, ihm zu Ehren wurde 1926 am Ring an prominenter Stelle ein großes Denkmal aufgestellt, das an den großen, legendären, 1910 gestorbenen Bürgermeister der Christlichsozialen erinnerte. Die Reichsratswahlen 1911 nach dem allgemeinen und gleichen Männerwahlrecht kündigten den Politikwechsel in Wien bereits an, der sich nach Gründung der Republik tatsächlich vollzog. Erstmals wurde in diesem Jahr die Sozialdemokratie zur stimmen- und mandatsstärksten Partei (42,9 Prozent, 19 Mandate), die Christlichsozialen verloren massiv (36,6 statt 49 Prozent, nur 3 statt 20 Mandate). Als Konsequenz aus diesem Debakel strebte die Lueger-Partei eine Neuorganisation der Partei an, wollte in der Zukunft eine breitere Wählerkoalition bilden. Auf Gemeinderatsebene blieb die Welt für die Christlichsozialen auch nach dem Tod Karl Luegers, ihres großen Erneuerers, noch heil, weil das Kurienwahlrecht die absolute christlichsoziale Mehrheit absicherte.

42. Kurt Kahl, Die Wiener und ihr Burgtheater, Wien/München, Jugend \& Volk, S. 97-115 ; Max Reinhardt. „Ein Theater, das den Menschen wieder Freude gibt...“. Eine Dokumentation, hrsg. von Edda Fuhrich und Gisela Prossnitz, München, Langen-Müller, 1987, S. 116140 ; Max Reinhardt. Leben für das Theater. Schriften und Selbstzeugnisse, hrsg. von Hugo Fetting, Berlin, Argon, 1989, S. 259f.

43. Markus Benesch, Die Wiener Christlichsoziale Partei 1910-1934. Eine Geschichte der Zerrissenheit in Zeiten des Umbruchs, Wien, Böhlau, 2014 ; Janek Wasserman, Black Vienna: The Radical Right in the Red City, 1918-1938, Ithaca, Cornell University Press, 2014. 
Die von der Opposition in der Vorkriegszeit vergeblich geforderte Mitwirkung an der Gemeindepolitik fand im Weltkrieg eine teilweise Erfüllung. Der Stadtrat wurde zwar nicht um Mandatare der Opposition erweitert, aber in der sogenannten Obmännerkonferenz waren Liberale und Sozialdemokraten eingebunden. Wie von der Stadtregierung damit ein Doppelspiel von Beteiligung und Ausschluss eröffnet wurde, so reagierten auch die Sozialdemokraten (Obmann Reumann und Winarsky, nach dessen Tod Skaret und in Vertretung Emmerling) mit Ambivalenz, immerhin wurden sie damit zu Agenten des Kriegsregimes. Die christichsoziale Stadtpolitik näherte sich, der Not des Krieges gehorchend, dem sozialdemokratischen Programm an, baute sukzessive die öffentliche Fürsorge aus, gründete kommunale Versorgungsbetriebe und führte den Mieterschutz ein, beschloss ein Wohnbauprogramm und bewegte sich sogar in der Steuerpolitik. Bei den Forderungen nach dem allgemeinen Wahlrecht gab es von Seiten des Wiener Bürgermeisters Richard Weiskirchner (Januar 1913 bis Mai 1919) Versprechen für die Zukunft.

Angesichts dieses Zusammenspiels war es nicht verwunderlich, dass Wien nach dem Umsturz im November 1918 auf Kontinuität setzte. Die Zahl der sozialdemokratischen Abgeordneten wurde auf 60 aufgestockt, die Christlichsozialen behielten weiterhin die (relative) Mehrheit von 84 Abgeordneten. Dass sie 19 Gemeinderatssitze aufgeben mussten, führte zu heftigen parteiinternen Auseinandersetzungen. Weiskirchner blieb weiterhin im Amt, bis die Wiener Gemeinderatswahl am 4. Mai 1919 die politische Gewichtsverteilung radikal veränderte. ${ }^{44}$

Während des Weltkriegs hatte sich eine Entfremdung der Bürgermeister-Partei und ihrer Wählerklientel vollzogen. Richard Weiskirchner wollte bei Kriegsbeginn durch einen besonderen Patriotismus auffallen und war als eine Art Zeremonienmeister an der Organisation der Kriegsbegeisterung in der Stadt führend beteiligt. Seine ohnehin nie berauschende Popularität schwand dahin, als es die Stadtverwaltung mit Fortdauer des Krieges immer weniger schaffte, die Bevölkerung ausreichend zu ernähren. Die eigene Wählerklientel wurde vor den Kopf gestoßen: Die Hausbesitzer wurden durch den Mieterschutz quasi enteignet, die Kleingewerbetreibenden fühlten sich brüskiert, weil sich

44. Maren Seliger/Karl Ucakar, Wien. Politische Geschichte. 1740-1934. Entwicklung und Bestimmungskräfte grossstädtischer Politik, Teil 2: 1896-1934, Wien, Jugend \& Volk, 1985, S. 981-987. 
die Stadt mehr und mehr in die Beschaffung, Produktion und Distribution einschaltete und damit den Prinzipien der Lueger-Politik abschwor. Den Beamten wurde eine adäquate Inflationsabgeltung mit der Begründung verweigert, dass der Schuldenstand der Stadt damit explodieren würde. Erwerb-, Grund- und Rentensteuer wurden kräftig erhöht. In der zweiten Hälfte des Krieges hungerte und fror auch der Mittelstand. Zudem trug zum Wählerverlust bei, dass ein erheblicher Teil der Partei bis zuletzt und über die Republikgründung hinaus sich emotionell und politisch der Monarchie verpflichtet fühlte. Mit viel Umsicht und Vorsicht sorgten Ignaz Seipel und der Kardinal dafür, dass eine Spaltung der Partei vermieden wurde und sich die Wiener Christlichsozialen an die republikanischen Zeiten adaptierten. Der monarchistische Flügel gab sich mit der Formel zufrieden, dass man in politisch ruhigeren Zeiten eine Volksabstimmung über die Staatsform (Monarchie versus Republik) abhalten wollte. ${ }^{45}$

Die Wahlen zur Konstituierenden Nationalversammlung am 16. Februar 1919 waren von den denkbar größten Spannungen begleitet. Eine in Wien bisher nie dagewesene Propagandaschlacht mit Plakaten, Flugblättern, Versammlungen und Lichtbildervorträgen versuchte die Bevölkerung zur Wahlbeteiligung zu motivieren. Noch hofften die Christlichsozialen, eine absolute Mehrheit der Sozialdemokraten zu verhindern. Aber die Ergebnisse der Nationalratswahlen in Wien waren eindeutig. Die Sozialdemokratie fuhr mit 55,4 Prozent der Stimmen einen großen Sieg ein, die bis 1918 absolut regierenden Christlichsozialen sackten auf 22,3 Prozent ab, die deutschnationalen Parteien wurden zu Kleinparteien reduziert. Bei den Gemeinderatsratswahlen verloren die Sozialdemokraten zwar leicht, die Christlichsozialen gewannen fünf Prozentpunkte dazu, aber bei der Mandatsverteilung blieben die Machtverhältnisse eindeutig: 100 der 165 Sitze fielen an die SDAP. Die Arbeiter-Zeitung jubelte bereits bei der Februar-Wahl: „Die Wiener Zahlen klingen wie eine berauschende Symphonie. ${ }^{\text {"46 }}$

In den ersten Monaten nach dieser politischen Zäsur herrschte weiterhin ein Klima der Zusammenarbeit ${ }^{47}$, aber dann kippte die politische Lage komplett in den Konfrontationsmodus. Der Ton wurde sichtlich rauer, der Druck im politischen Kessel Wien größer. Die Christlichsozi-

45. Markus Benesch, Die Wiener Christlichsoziale Partei 1910-1934, op. cit, S. 21-57.

46. Arbeiter-Zeitung, 17.2.1919, S. 1.

47. Maren Seliger/Karl Ucakar, op. cit., S. 1048-1053. 
alen, denen nun klar wurde, dass sie in ihrer alten Hochburg zur ungeliebten Oppositionsrolle verdammt sein würden, zogen populistisch mit allen verfügbaren Vorwürfen in die Schlacht gegen die rote Mehrheit. Die schlechte Versorgung wurde gegen die neue Stadtverwaltung verwendet, die Agitation gegen den Steuersadismus hochgeschraubt, im Antisemitismus überschritt die von Leopold Kunschak geführte Stadtpartei die bis dahin üblichen Grenzen und forderte den Numerus Clausus an den Universitäten und Konzentrationslager für ostjüdische Flüchtlinge, in den sozialdemokratischen Sozialprogrammen und den Aktivitäten der Arbeiter- und Soldatenräte witterte man „schleichenden Bolschewismus“. Unter dem Titel „Gibt es für Wien noch eine Rettung?" wurde etwa am 1. Dezember 1919 eine Massenversammlung in die Volkshalle einberufen, durch die sich die Rathausmehrheit provoziert fühlte. Dass die Kundgebung von der aufmarschierenden Volkswehr und Arbeitern des Gaswerkes gesprengt wurde, heizte das gespannte politische Klima noch weiter an. Immerhin war es möglich, dass die etwa 2000 Kundgebungsteilnehmer im geschlossenen Zug in das Gumpendorfer Gesellen-Vereinshaus auswichen, wo Leopold Kunschak in seiner Brandrede vor allem über den Einfluss der Arbeiter- und Soldatenräte herzog und als „Bilanz des Umsturzes“ resümierte:

Dass wir so tief gesunken sind, findet seine Erklärung darin, dass bei uns alle Kräfte nur der Zerstörung und Auflösung gewidmet scheinen und so gar niemand der Ruhe und Ordnung dienen will. [...] Wir haben eine vor dem Gesetz verantwortliche staatliche und öffentliche Verwaltung, das alles aber nur auf dem Papier. In der Praxis sind wir eine Räterepublik, ein Bolschewistenstaat. ${ }^{48}$

\section{Das Neue Wien}

„Was fordern die Sozialdemokraten von der Gemeinde Wien?" ${ }^{\text {49 }}$ Das war der Titel des sozialdemokratischen Kommunalprogramms, das - nach Vorläufern seit $1896^{50}$ - kurz vor dem Ersten Weltkrieg im Jahr

48. Reichspost, 2.12.1919.

49. Was fordern die Sozialdemokraten von der Gemeinde Wien? Das sozialdemokratische Kommunalprogramm, Wien, Verlag der Wiener Volksbuchhandlung, 1914.

50. Felix Czeike, „Wien“, in Erika Weinzierl/ Kurt Skalnik, Österreich 1918 - 1938, Graz, Styria, 1983, Band 2, S. 1045. 
1914 beschlossen wurde. Die Forderung nach dem allgemeinen Wahlrecht für Männer und Frauen ab dem 20. Lebensjahr, nach Aufhebung der Wahlkörper und der Einführung des Proporzsystems waren Eckpfeiler des Manifests. Verlangt wurde auch die Loslösung von „der reaktionären Majorität des niederösterreichischen Landtages" durch Schaffung einer Reichunmittelbarkeit Wiens. Die Wahl des Bürgermeisters sollte in Zukunft keine Bestätigung mehr durch den Kaiser benötigen. Weiters wurde die Beseitigung der bisherigen rigiden Form des Heimatrechts - 1910 hatten bloß 55,6 Prozent der Bewohner eine Heimatberechtigung - verlangt. Der Hauptteil des Programms galt der Sozialpolitik, dem Armenwesen, der Arbeiterfürsorge, dem Gesundheitswesen, dem Wohnungswesen und dem Schulwesen. Grundsätzliche Änderungen verlangte man im Steuerwesen: Reduzierung der Massensteuern, Einführung einer städtischen progressiven Einkommens- und Vermögenssteuer und einer progressiven Erbschaftssteuer. Mit der Festlegung der drei großen Schwerpunkte Wohnungs-, Fürsorge- und Bildungspolitik lag mit diesem Dokument in nuce das Programm des Roten Wien vor.

Die Gemeinderatswahlen 1919 beendeten die seit 1895 bestehende Hegemonie der Christlichsozialen Partei. Jakob Reumann wurde der erste sozialdemokratische Wiener Bürgermeister. ${ }^{51}$ In den ersten Monaten und Jahren des Neuen Wien fielen große Entscheidungen mit enormen Folgewirkungen, wurden die Grundlagen des Roten Wien gelegt. Aber wer nahm in der damaligen Zeit die Ankündigung der sozialdemokratischen Politiker, in Wien eine sozialdemokratische Musterstadt zu bauen, wirklich ernst? Die unter extremer Schuldenlast leidende, fast bankrotte Stadt bewegte sich damals im permanenten Krisenmodus. Kein Denken, dass diese „sterbende Stadt" ihrem Dilemma entkommen und ein weltweit bewundertes Modell generieren könnte.

Vorrangigste Aufgabe der neuen Wiener Stadtregierung war die Sanierung von „Wiens trauriger Finanzlage“ ${ }^{52}$, die zum Zeitpunkt der Wahlen aus einem enormen, vor allem während des Weltkriegs angesammelten Schuldenberg von 250 Millionen Kronen bestand. Im sozialdemokratischen Team der ersten Stunde war Hugo Breitner als künftiger Finanzstadtrat bereits dabei; der ausgewiesene Finanzexperte sollte eine schrittweise Umstellung des Wiener Steuer- und Abgabensystems einleiten. Während sich vor dem Krieg die Stadt Wien fast ausschließlich

51. Franz Patzer, Der Wiener Gemeinderat 1918 - 1934. Ein Beitrag zur Geschichte der Stadt Wien und ihrer Volksvertreter, Wien, Jugend \& Volk, 1961, S. 62-71.

52. Maren Seliger/Karl Ucakar, op. cit., S. 1057-1079 ; Arbeiter-Zeitung, 10.4.1919, S. 1-2. 
aus indirekten Massensteuern, vor allem aus einem Mietzinszuschlag und den lukrativen Gewinnen der kommunalen Unternehmen finanziert hatte, setzte Breitner programmatisch mit "Wertzuwachsabgabe“, „Lustbarkeitsabgabe“, „Luxussteuern“ auf einen Neubeginn. Kurzfristige Zahlungsziele und in Prozenten gerechnete Steuersätze führten zu einem strengen Regime bei der Einhebung. Aber diese neuen Steuern sanierten nicht das Budget. Erst die Einführung von Massensteuern, einer progressiv gestalteten Abgabe auf den Mietzins, welche Mieten unter 900 Kronen ausklammerte, und der im Juli 1920 beschlossenen Fürsorgeabgabe, einer Art Lohnsummensteuer, brachte die Wende. ${ }^{53}$ Die städtischen Unternehmen wurden entgegen verlockenden Angeboten nicht verkauft und die diversen Abgaben für Wasser, Kanalisation und Energie kostendeckend erhöht. ${ }^{54}$ Die Anfänge des „Roten Wien“ waren also nicht durch den später berühmten kommunalen Wohnbau gekennzeichnet, sondern durch die Steuerpolitik. Zu Hilfe bei der Budgetsanierung kam der Stadt Wien die exorbitante Inflation. Die Anleiheschulden im Inland konnten im Wesentlichen bereits bis 1923 zurückgezahlt werden.

Gleichzeitig mit der Sanierung des Budgets ging die sozialdemokratische Stadtregierung das Projekt einer neuen „demokratischen Stadtverfassung ${ }^{\text {"55 }}$ an, das die bisherigen Entscheidungsmechanismen und Regierungsregeln gründlich veränderte. An Stelle eines bisher allmächtigen Bürgermeisters und eines wenig einflussreichen Kollegialgremiums („Stadtrat“) trat eine Ressortverantwortung. Stadträte, in Permanenz begleitet durch die Beratungen und Beschlüsse der jeweiligen Gemeinderatsausschüsse, betreuten nun bestimmte Aufgabenbereiche und führten den jeweiligen Beamtenapparat. Wie in den anderen Bundesländern bereits eingeführt, war ursprünglich auch in Wien eine Proporzregierung vorgesehen. Nach den Erfahrungen mit dem Koalitionsbruch Mitte 1920 und der Marginalisierung sozialdemokratischer Regierungsmitglieder in manchen Bundesländern wurde in Wien allerdings eine Regierungsbeteiligung der Opposition (Unterscheidung zwischen amtsführenden und nicht-amtsführenden Stadträten) minimiert.

Als drittes Großprojekt stand die Klärung des Verhältnisses zwischen

53. Wolfgang Fritz, Der Kopf des Asiaten Breitner: Politik und Ökonomie im Roten Wien. Hugo Breitner, Leben und Werk, Wien, Löcker, 2000.

54. Felix Czeike, Wirtschafts- und Sozialpolitik der Gemeinde Wien, 2 Teile, Wien, Jugend \& Volk, 1958/59, S. 124-138.

55. Seliger/Ucakar, Wien, op. cit., S. 1022-1056. 
Niederösterreich und Wien ${ }^{56}$ an, die bislang ein gemeinsames Kronland mit Wien als Hauptstadt bildeten. Die Trennung wurde in ihrer Sinnhaftigkeit, Ausgestaltung und territorialen Abgrenzung immer wieder in Frage gestellt. Die Verhandlungen zeigten ein komplexes Konfliktpotential. In den einzelnen Parteien standen unterschiedliche Interessen gegeneinander. Ein erster Anstoß zur Trennung von Niederösterreich-Land und Wien gab es nach den Wahlen im Februar und Mai 1919. Der generelle Befund des Wahlergebnisses war eindeutig: Niederösterreich war politisch gespalten. Das ländliche Niederösterreich war christlichsozial dominiert, seine Landeshauptstadt Wien dagegen sozialdemokratisch. In Addition der beiden Teile hatte das Land Niederösterreich dank der herausragenden Stellung Wiens eine sozialdemokratische Mehrheit.

Bei den gesamtösterreichischen Länderkonferenzen der Jahre 1919/1920 nahm ein anderes Forum die Brisanz des Verhältnisses Wien-Niederösterreich auf. Diesmal war der Ausgangspunkt der Vergleich der Bevölkerungsstärke zwischen den verschiedenen Bundesländern; eher kleinen Bundesländern mit zwei bis sechs Prozent der Bevölkerung (nach der Reihenfolge ihrer Größe: Vorarlberg, Salzburg, Burgenland, Tirol und Kärnten) standen solche mittlerer Größe von 12 bis 15 Prozent (Oberösterreich, Steiermark) gegenüber. Niederösterreich mit Wien war das Schwergewicht in der Phalanx der Bundesländer (52,8 Prozent). Die bevölkerungsmäßige Dominanz im Osten löste bei den westlichen und südlichen Bundesländern heftige Kritik aus. Als Mindestforderung deponierten sie bei den Länderkonferenzen eine Trennung der beiden Länder. Mochten Wien und Niederösterreich weiterhin auch die gleiche Hauptstadt und den gleichen Sitz als Landtag haben, als Länder sollten sie getrennte Wege gehen.

Wie die Trennung von Wien und Niederösterreich ablaufen sollte, war in ihrer konkreten Umsetzung zunächst keineswegs klar. So sehr sich die Christlichsozialen in Wien und die Sozialdemokraten in den Städten des Wiener Umlands auch wehrten, die komplette Trennung der Bundesländer Wien und Niederösterreich wurde 1921 Realität. Der Wiener Bürgermeister Jakob Reumann war ein Verfechter der Separierung von Wien und Niederösterreich, nicht zuletzt wegen der Steuerkompetenz, die Wien als Bundesland zustand. Damit konnte sich die politische Energie der Sozialdemokratie auf die Großstadt Wien und deren Probleme konzentrieren, ohne gleichzeitig die Entwicklung des

56. Ebenda, S. 996-1009. 
Agrarlandes berücksichtigen zu müssen. Die geplante Wohnbautätigkeit wurde zwar durch den Ankauf von Boden vorbereitet, aber der offizielle Start der spektakulären Wohnungspolitik, die in Etappen zum Bau von 65000 Gemeindewohnungen führte, erfolgte erst 1923.

\section{Der Sumpf}

In der Innenstadt war das „sterbende Wien“ nicht zu sehen und spüren. Die Wiener City zog einen gar nicht so kleinen Teil der Gesellschaft an, der von der Inflation profitierte und gewillt war, das schnell verdiente Geld auch schnell wieder auszugeben. Angereiste Touristen und Journalisten, die eine Bettelstadt erwarteten, waren erstaunt, was sich ihnen in und um den Ersten Bezirk bot. Von Elend war hier nichts zu sehen. Die Restaurants waren voll, die Speisekarten boten ohne Einschränkung die Wiener Spezialitäten an, die Vergnügungsstätten im Prater brauchten über Nachfrage nicht zu klagen. Für skandalumwitterte Events und spektakuläre Aufführungen (wie die Opernpremiere von Richard Strauss' Frau ohne Schatten) wurden exorbitante Preise bezahlt. Alle Hotels und Pensionen waren bis auf den letzten Platz seit Monaten belegt, Wien lag den Fremden und Ausländern zu Füßen und trachtete ihnen Devisen zu entlocken, indem man ihnen Luxus bot und den Ausverkauf von Antiquitäten betrieb. Das Zentrum inszenierte sich als Überfülle des Reichtums, grelle Spielhöllen und Nachtklubs lockten mit neuartigen Jazzrhythmen und exotischen Tänzen Publikum an. Die Konzertcafés vervielfachten sich. In den Straßen der Innenstadt, in den Theatern, Konzerten, Cabarets, Kaffeehäusern ging es lebhaft zu. Geld spielte keine Rolle, Geld war zum Ausgeben da. Wien war wieder, wie anno dazumal, ein Mekka der Vergnügungs- und Kulturszene.

In Zeitromanen wurde „Das entfesselte Wien“ zum großen Thema: Bestsellerautor Hugo Bettauer schrieb Romane über eine zügellose Stadt zwischen großem Geld und extremer Not, mit Schiebern und jungen Mädchen, die ihnen zum Opfer fallen. Jazz, so der Titel eines Romans von Felix Dörmann ${ }^{57}$, wurde zum Zeichen eines Verfalls, dem die alte Wiener Gesellschaft zum Opfer fiel. Die Feuilletons sind voll mit Geschichten über die Inflationsjahre. „Man kann nichts verdienen,

57. Felix Dörmann, Jazz: Wiener Roman, Warnsdorf, Strache, 1925. 
wenn man arbeitet ${ }^{\text {“58, }}$, schrieb Joseph Roth in einem seiner Wien-Texte. Geld wurde in Cafés, Hotelhallen und den vielen neu gegründeten Banken verdient. Die Schwankungen zwischen Kronen, Mark, Lire und Dollars werden nicht nur von Spekulanten genutzt, wenn die Preise der Waren über Nacht anzogen, zogen auch einfache Ladeninhaber ihren Gewinn. Antiquitäten und Kunstgegenstände waren billig zu haben. Valuta „ist das Zauberwort, das alles Denken und Fühlen, alle Gemüter, Pläne und Beziehungen beherrscht ${ }^{\text {"59 }}$, klagte der bürgerlich-liberale Feuilletonist Ludwig Hirschfeld und gab sich Untergangsstimmungen hin.

Die Rechte bündelte alle Zeitphänomene in einen wilden, diffusen populistischen Hass gegen die Linke. In einer reaktionären Grundstimmung wurden alle Phänomene der Gegenwart so lange gewendet, bis sie sämtliche Klischees und hasserfüllten Vorurteile bedienten. Es gab durchaus noch Steigerungsformen in der negativen Beurteilung Wiens. Zu den Zuschreibungen als „Wasserkopf“, „Beamtenburg“, „rotes Wien“, $\mathrm{zu}$ allen Fantasien über einen Rückbau Wiens auf eine dem neuen Staat gemäße Hauptstadt fügte sich ein Image ein, das aus dem Antisemitismus spross und die „österreichische Revolution“ als Kombination von Bolschewismus und Moderne verortete: Wien wurde zum Sündenbabel schablonisiert, das mit seiner Sitten- und Glaubenslosigkeit, mit seinen „Sever"-Ehen seinen Kino- und Theateraufführungen, mit seinen Homosexuellen-Partys und Stundenhotels, mit seinen modisch-kokett gekleideten Frauen (Seidenstrümpfe, kurze Röcke, Bubikopf), mit seinem Nachtleben (Konzertcafés, Bars, Jazztänze) das gesamte Land kulturell gefährdete und von dem eine Ansteckungsgefahr ausging. Der Sozialismus war der Weg in die eigentums- und verantwortungslose Anarchie, die Moderne das Tor zur Sittenlosigkeit. Wien war der "Sumpf“. Das Judentum mit seiner „Destruktivität“, seinen anderen Werten, seiner rassischen Fremdartigkeit war dabei der Drahtzieher, der sich die Zerstörung des christlichen Abendlandes als Ziel gesetzt hatte. Die Sozialdemokratie, die die liberalen Freiheiten verteidigte, agiere als willfährige „Judenschutztruppe“, was nicht verwunderlich sei, da ja an ihrer Spitze viele Juden ihre Politik lenken würden.

Recht unmittelbar kamen diese Verschwörungsfantasien in der rech-

58. Joseph Roth, „Die Rentabilität der Faulheit“, in Joseph Roth: Das journalistische Werk 1915 1922, hrsg. von Klaus Westermann, Köln, Kiepenheuer \& Witsch, 1989, S. 199.

59. Ludwig Hirschfeld, „Das papierene Kalb“, in Ludwig Hirschfeld, Wo sind die Zeiten ...: Zehn Jahre Wien in Skizzen, Wien, Wila, 1921, S. 251. 
ten belletristischen Literatur zu variantenreichen Ausprägungen. ${ }^{60}$ Der Titel eines Romans des Vielschreibers Karl Hans Strobl brachte 1920 den postrevolutionären Zustand Wiens auf den Begriff: Gespenster im Sumpf. ${ }^{61}$ Er schilderte ein zwanzig Jahre nach der Republikgründung völlig verkommenes, zerstörtes, von der Außenwelt abgeschottetes Wien, das von einer verrückt gewordenen sozialdemokratischen Führung regiert wird, in der die Menschen jede Lust auf Arbeit, „Ehrfurcht, Bescheidenheit und Pflichtgefühl“ verloren haben, in der mit Streiks und Rätediktatur in der „Republik Morgenstern“ Chaos und Kampf aller gegen alle ausbricht. Der katholische Autor Friedrich Schreyvogel überschrieb seinen fantastischen Roman über das Wien der Jahre 1918/19 mit dem Titel Der Antichrist ${ }^{62}$, in der fanatisierte Massen mittels eines perfekten Propagandaapparats von dämonischen Führern manipuliert werden. Beide Romane haben eine unübersehbar antisemitische Stoßrichtung. Das bösartigste und skurrilste Beispiel dieser antirepublikanischen, antisemitischen Literaturproduktion war der Roman Repablick (1924) von Karl Paumgartten ${ }^{63}$, in dem von der Entente bezahlte Revolutionäre der unbesiegten österreichischen Armee in den Rücken fallen und sozialdemokratische Führer und kommunistische Gewalttäter, natürlich immer Juden, sich prächtig ergänzen: „Der rote Führer ist das feigste Luder: / Zum Taschenfüllen nur reicht hin sein Eifer. / Zu Taten liefert er nichts als Geifer, / Den Mut zum Handeln hat sein - Plattenbruder." ${ }^{\text {"64 }}$ Paumgartten verstand es, seinen monströs-deftigen Antisemitismus in verschiedenen Medienformen zu verwerten. Er schrieb Hetzschriften in Broschürenform, er war Beiträger von dezidiert paranoiden Tableaus in den Wiener Stimmen (einem Ableger der christlichsozialen Reichspost), später in der pränationalsozialistischen Deutschösterreichischen Tageszeitung (DÖTZ).

Paumgartten schaltete sich auch immer in die österreichischen Kulturkämpfe ein. Eine Gelegenheit dazu, die er sich nicht entgehen ließ, bot sich ihm in der Staatsaffäre um die Aufführung von Arthur Schnitzlers Reigen im Februar 1921, in der die Kampagne gegen den Sumpf mit

60. Friedrich Achberger, Fluchtpunkt 1938. Essays zur österreichischen Literatur zwischen 1918 und 1938, Wien, Verlag für Gesellschaftskritik, 1994, S. 101-131.

61. Karl Hans Strobl, Gespenster im Sumpf: Ein phantastischer Wiener Roman, Leipzig, Staackmann, 1920.

62. Friedrich Schreyvogl, Der Antichrist, Wien/Leipzig, Wiener Graphische Werkstätte, 1921.

63. Karl Paumgartten, Repablick: Eine galgenfröhliche Wiener Legende aus der Zeit der gelben Pest und des roten Todes, Graz, Heimatverlag L. Stocker, 1924.

64. Achberger, Fluchtpunkt 1938, op. cit., S. 128. 
der Austreibung des Theaterpublikums aus den Kammerspielen seinen politisch-theatralischen Kulminationspunkt fand. Alle Foren wurden aktiviert, um diesen Kulturkampf zu führen. Die einzelnen Etappen dieses Skandals waren umgeben von groteskem apokalyptischen Stimmengewirr und zuspitzendem Aktionismus. Der Fastenhirtenbrief der österreichischen Bischöfe, journalistische Kampagnen, Parlamentsund Gemeinderatsdebatten mit Raufereien, Massenversammlungen mit Reden führender christlichsozialer Politiker und des Wiener Kardinals leiteten die Eskalation ein, die mit der von einem ehemaligen Offizier der Frontkämpfervereinigung angeführten Erstürmung des Theaters abgeschlossen wurde. Der Reigen-Skandal landete schließlich vor dem Verfassungsgerichtshof. Der massive Einsatz von Gewalt gegen das Theaterpublikum, der nur durch Zufall keine Toten und Schwerverletzten hinterließ, wurde in der rechten Presse als „Verjagung des jüdischen Schieberpublikums" gefeiert.

\section{Der Schmelztiegel}

Wien strahlte auf alle Bewohner der Monarchie aus, junge Menschen in der ganzen Monarchie, wie etwa Manès Sperber im galizischen Zablotow, wurden gar von „leidenschaftlicher Liebe ${ }^{\text {“65 }}$ zur Reichshauptund Residenzstadt erfasst, deren Glanz und Größe sie aus der Ferne über alle Maßen bewunderten. Wien zog an, versprach Arbeit, Chancen und Aufstieg und wirkte als Schmelztiegel aller Nationalitäten der Monarchie. Bildung, Kultur und Arbeitschancen wirkten als Assimilationsfaktoren. Gleichzeitig legten die Bürgermeister von Lueger bis Weiskirchner größten Wert darauf, Wien als „deutsche Stadt“ zu erhalten und zogen viele administrative Register, diese nationale Exklusivität zu unterstützen.

Wien war eine Zuwandererstadt. 1880 waren nur 38,5 Prozent der Einwohner in Wien geboren, 1910 waren es immerhin 48,8. Die Zuwanderung aus den heutigen österreichischen Bundesländern betrug etwa 15 Prozent. Wie sehr Wien mit den 1918 abgetrennten böhmischen und

65. Manès Sperber, Die Wasserträger Gottes, in M. S., All das Vergangene...., Wien, Europaverlag, 1983, S. 168. 
mährischen Gebieten verbunden war, zeigte die Bevölkerungsstatistik aus dem Jahr 1910: 23 Prozent der Wiener Bevölkerung, also knapp 500 000, stammten von dorther und stellten alle anderen Zuwanderergruppen in den Schatten. Wie groß dabei die Gruppe mit tschechischer und slowakischer Muttersprache war, ist retrospektiv nicht mehr genau auszumachen. Historiker schätzen sie um etwa 300000 ein. Sie waren in Wien hauptsächlich als Arbeiter, Taglöhner und Dienstboten beschäftigt. Fast 50 Prozent der weiblichen Hausbediensteten (Köchinnen, Wäscherinnen, Kindermädchen) waren böhmischer bzw. slowakischer Herkunft. ${ }^{66}$

Nach 1890 wuchs auch die jüdische Zuwanderung stark, um 1910 waren 175000 (8,6 Prozent) der mehr als 2 Millionen zählenden Bevölkerung mosaischen Glaubens. Es gab dabei zwei sehr unterschiedliche Trends. Viele schafften durch die Bildungsorientierung den Sprung in die Mittelschichten und Eliten und passten sich kulturell an die neue Umgebung an. ${ }^{67}$ Die Kreativität der jüdischen Zuwanderer zeigte sich oft in der zweiten Generation: Die Kunst des Wiener Fin-de-siècle war stark durch die mentale Krise des assimilierten Judentums geprägt. Gleichzeitig gab es im Wiener Bezirk Leopoldstadt eine starke Ghettoisierung; die Zuwanderer aus dem Osten lebten dort ihre eigene, relativ geschlossene (religiöse) Kultur. ${ }^{68}$ Mit der Massenflucht aus den Kriegsschauplätzen Galizien und Bukowina nahm die jüdische Bevölkerung während des Ersten Weltkrieges nochmals zu. Nach den ersten russischen Offensiven im Herbst 1914 strandeten bis zu 200000 ostjüdische Flüchtlinge in Wien. Nach der Rückeroberung Galiziens ging die Zahl stark zurück, um bei der Brussilow-Offensive wieder anzusteigen. Nach dem Krieg kehrten zwar viele in ihre Herkunftsregionen zurück, aber der Krieg zwischen Polen und der Ukraine bzw. der Sowjetunion, der zu Lasten der jüdischen Bevölkerung ausgetragen wurde, führte wiederum zur Massenflucht. Wien wurde auch zur Relaisstation für die Auswanderung in die USA oder nach Palästina. Mit der Republikgründung kam dann der schon im Krieg anschwellende, allerdings unterdrückte Antisemitismus in aller Macht zum Vorschein; die Hetze gegen die ostjüdischen Flüchtlinge spielte bei den Wahlen 1919 und in

66. Schmelztiegel Wien - einst und jetzt. Zur Geschichte und Gegenwart von Zuwanderung und Minderheiten. Aufsätze, Quellen, Kommentare von Michael John und Albert Lichtblau, 2. verb. Aufl., Wien, Böhlau, 1993, S. 11-20.

67. Steven Beller, Wien und die Juden 1867-1938, Wien, Böhlau, 1993.

68. Marsha L. Rozenblit, Die Juden Wiens 1867-1914. Assimilation und Identität, Wien, Böhlau, 1988. 
der Inflationszeit eine wichtige Rolle im politischen Leben. 1923 wurden bei der Volkszählung 201513 Personen mosaischen Glaubens in Wien gezählt.

Wien wie Österreich wurden nach der Auflösung der Monarchie national homogener. Es gab keinen Sprachenstreit mehr im neuen Staat Deutschösterreich, die lautstarken Nationalitätenkonflikte im Reichsrat waren nunmehr unselige Vergangenheit. Italienische, jugoslawische, ungarische Minderheiten verließen Wien, trotzdem fungierte die Stadt nach wie vor als ein gewisser Schmelztiegel. Trotz des Bevölkerungsrückgangs waren erhebliche Migrationsbewegungen zu beobachten. Gerade im Kultur-, Vereins- und religiösem Leben zeigte sich der Reichtum von Post-Habsburg. In Wien wurde jiddisches Theater gespielt, wurden jiddische Romane publiziert. Die Emigration aus Ungarn nach dem Sturz der Räterepublik ergab einen erheblichen Zuwachs an hervorragenden kreativen Kräften für die Kultur- und Wissenschaftsszene. In der Volkszählung 1923 wurden für Wien knapp 80000 Einwohner mit Tschechisch/Slowakisch als Umgangssprache ausgewiesen. ${ }^{69}$

Die demographischen Strömungen nach 1918 lassen sich nach den offiziellen Statistiken schwer nachvollzuziehen, denn die erste Nachkriegsvolkszählung fand erst 1923, also erst nach den stürmischen Jahren des Staatszerfalls, statt. Wiens Bevölkerung erreichte während des Krieges einen Höchststand von etwa 2,3 Millionen Einwohnern. Mit Kriegsende setzte aus vielerlei Gründen ein Schrumpfungsprozess ein, 1923 wies Wien nur mehr 1,86 Millionen Einwohner auf. 150000 bis 200000 Bewohner verließen die Stadt in Richtung der neuen, Prosperität verheißenden Tschechoslowakei. Viele Stadtbewohner übersiedelten wegen der besseren Versorgungsmöglichkeiten auf das Land, auch die Auswanderung aus der Elendsmetropole war ein Faktor. Gleichzeitig strömten viele Gruppen aus den deutschsprachigen Gebieten der neuen Nationalstaaten nach Österreich. Auch nach dem Krieg versuchten ostjüdische Flüchtlinge den militärischen Auseinandersetzungen zwischen Polen, der Ukraine und der Sowjetunion zu entkommen. Zur ungarischen Emigration während und nach der Räterepublik gibt es wenig statistisches Material, angeblich flohen im Herbst 1919100000 in den Westen.

69. Michael John, „Der lange Atem der Migration - die tschechische Zuwanderung nach Wien im 19. und 20. Jahrhundert", in Tschechen in Wien. Zwischen nationaler Selbstbehauptung und Assimilation, Wien, Löcker, 2010, S. 31-60. 
Wie sehr das Nachkriegs-Wien weiterhin als Schmelztiegel fungierte, zeigte sich bei den ersten Nationalrats- und Gemeinderatswahlen 1919. Die kandidierenden ethnisch klar definierten Parteien konnten bei weitem nicht ihr Reservoir bei ihrer Sprach- und Religionsgruppe ausschöpfen, aber immerhin machte ihr Einzug in das Stadtparlament deutlich, dass sie Faktoren in der Stadtpolitik waren, mit denen man rechnen musste. Bei der ersten Sitzung des Gemeinderats produzierte die Partei der sozialistischen und demokratischen Tschechoslowaken einen Eklat, weil sie ihre Rechte in einem demokratischen Wien anmeldeten. Immerhin hatten sie 8,4 Prozent der Stimmen und 8 Mandate erobert. Als ihr Redner die Zulassung des Tschechischen als offizielle Verhandlungssprache forderte, begannen Christlichsoziale und Deutschnationale, ganz im Denken der Lueger-Zeit, aus Protest den Sitzungssaal zu verlassen. Daraufhin setzte Antonín Machát seine Rede auf Tschechisch fort, worauf ihm Jakob Reumann, der den Vorsitz führte, das Wort entzog. Damit endete die erste Sitzung des neuen Gemeinderats. ${ }^{70}$ Immerhin wurde eine Streitbeilegung mit den Wiener Tschechen erreicht, indem private Comenius-Schulen zugelassen und auch öffentliche Schulen mit Tschechisch-Unterricht eingerichtet wurden. Mit der zunehmend politischen Konfrontation allerdings verschwand die Partei aus dem Gemeinderat, indem diese Partei von den Sozialdemokraten aufgesogen wurde. Antonín Machát zog etwa als sozialdemokratischer Mandatar aus Favoriten ins Stadtparlament ein.

Die starke jüdische Minderheit war politisch und kulturell zersplittert. In der Mehrheit fand sie bei der Sozialdemokratie ihre politische Heimat, ein Teil bei den „Demokraten“. Viel Diskussion innerhalb der jüdischen Gemeinde löste 1919 das Antreten einer zionistischen „Jüdischen Partei" aus, die bei der Mehrheit der assimilationsorientierten Juden einen schweren Stand hatte. 1919 kamen die Zionisten mit einem Mandat in den Nationalrat und drei in den Gemeinderat. 1923 erzielten sie zwar bei den Gemeinderatswahlen stimmenmäßig das relativ beste Ergebnis, aber wegen der wesentlich höheren Wahlbeteiligung wurde sie bei den Mandaten auf einen einzigen Vertreter reduziert. Bei den polarisierenden Wahlen 1927 gelang der Partei nicht mehr der Einzug in den Gemeinderat. ${ }^{71}$

70. Patzer, Wiener Gemeinderat, op. cit., S. 77.

71. Maren Seliger/Karl Ucakar, Wahlrecht und Wahlverhalten in Wien 1848-1932. Privilegien, Partizipationsdruck und Sozialstruktur, Wien, Jugend \& Volk, 1984, S. 139-145 und S. 169f. 